Indonesian Journal of EFL and Linguistics

Vol. 4 No. 1, 2019

eISSN: 2503-4197, pISSN: 2527-5070

www. indonesian-efl-journal.org

\title{
Interactional Strategies and Anaphoric Repairs of BS Information and Communications (BSIT) Technology Students
}

\author{
Kevin Lacia ${ }^{1}$, Julea Nathalie Ginco ${ }^{1}$, Rowanne Marie Ramos Maxilom- \\ Mangompit $^{2}$ \\ University of San Carlos, Philippines ${ }^{1}$ \\ Cebu Technological University Philippines ${ }^{2}$ \\ e-mail: rowannemarie.mangompit@ctu.edu.ph
}

\begin{abstract}
:
This study aimed to analyze the interactional strategies and anaphoric repairs used in the recorded pair conversations of the Bachelor of Science in Information and Communication Technology (ICT) students who were taking the course ICT 135 (Interactive English). The present research analyzed the ten recorded pair conversations. The results revealed the questions, minimal responses, and making statements predominated among the interactional strategies while the anaphoric repairs included other-initiated self-repair and self-initiated other-repair. This study provides implications to classroom interaction and use of language in interacting with other students. Future researchers can let their participants use their Mother Tongue or the Cebuano language as the language to be used in their research, regardless of the subject taken up by the participants. In using the Mother Tongue, the participants would be more comfortable in speaking providing a more natural and unrestricted flow of conversation.
\end{abstract}

Keywords: anaphora, discourse, interactional strategies, repair 


\section{Rowanne Marie Ramos Maxilom}

\section{INTRODUCTION}

As human beings who are given the ability to think, people are inclined to communicate or share information. Communication is an integral part of our lives and it is practiced everyday everywhere. Communication is defined by Pearson, Nelson, Titsworth \& Harter (2003) as the action in which meaning is exchanged between individuals through a common system of symbols, signs or behaviors. Language is one of those common systems of symbol and it allows people to communicate with one another. One instance of communication where the constant usage of language by man is evident is in conversations.

According to Stockwell (2007), conversations are incorporated with utterances which correspond to the sentences taken in their social context including a sense of situation of the speaker and hearer, the purpose of the utterance, and the effect of the utterance. They are produced not simply by the presence of the speakers alone, but also by the display of their continuing agreement to pay attention to one another. They are cooperative activities because they involve two or more parties, each of whom must be allowed the opportunity to participate as pointed out by Wardhaugh(2010). In other words, people use a "variety of strategies to ensure, encourage and subvert conversation" (Fishman, 1983 in Bonvillain, 2003, p.204).

On the other hand, anaphoric production by the listener and the speaker is also present in conversations and this crucially depends on the assumptions made by the speaker about how the hearer will recognize the intended referent. The mistakes created by the speaker or the listener will sometimes lead to anaphoric repair according to Levelt (1989, in Huang, 1989).

By studying the conversation of students in a casual setting, the researchers could provide concrete examples in a local setting that there are actually strategies and repairs in conversations and these are used for the continuance of the conversation as well as for the correction of anaphoric production. The researchers specifically chose a class taking up the course ICT 135 or 'Interactive English' because the said course focused on interaction among people. Interaction is the very foundation of this present study. Thus, this study analyzed the conversations among one BS Information and Communication Technology (ICT) class taking up 'Interactive English' to identify what interactional strategies and anaphoric repairs were used.

\section{LITERATURE REVIEW}

This review is composed of topics as follows: Interactional Strategies and Discourse Anaphora. First, interactional sociolinguistics (IS) is "an approach to discourse analysis that has its origin in the search for replicable methods of qualitative analysis that account for our ability to interpret what participants intend to convey in everyday communicative practice" (Gumperz, 2008, p. 215). It is well-known that people engaged in conversation always rely on knowledge that goes beyond grammar and lexicon to make themselves heard (Gumperz, 2008, p. 215). According to Tannen 
(2005), "interactional sociolinguistics (IS) researchers or IS itself, tend to focus on intercultural interaction because the ways in which language works to create meaning in interaction stand out in relief when expectations regarding their use are not shared...." (p. 205).

There are more than one form of interactional strategies as derived from Fishman's (1983, in Coupland and Jaworski, 1997) study. The first mentioned strategy is asking questions. This is explained by Bonvillain (2003), as understood from Fishman (1983) that questions guarantee a successful talk because they are very surely to be paired with answers. Fishman (1983) further explained by saying that questions are interactionally powerful utterances and that they are among the class of utterances like greetings. Questions are treated as standing in paired relation because they evoke further utterance.

Moreover, asking 'd'ya know what' works like the former interactional strategy. Only, these ritualized questions trigger a three-part exchange of the form: question-questionanswer as compared to Asking Questions which follow the question-answer exchange form as shown below from Fishman (1983, in Coupland and Jaworski, 1997):

$$
\begin{array}{rlll}
5 \quad \mathrm{~F} \quad: & \text { Ok. That's a change. (72) Hmm. That's } \\
& \text { very interesting. Did }
\end{array}
$$

Another form of strategy is attention beginning. Bonvillain (2003) defined this as expressions which are used to establish the interest or legitimacy of statements or topics to follow. An example of attention beginnings is "this is interesting" (Fishman, 1983, in Coupland and Jaworski, 1997). Minimal responses which are sometimes called 'back-channels' are forms "such as yeah or right or mhm" (Coates, 2004, p. 87). These are the nods or approval or other gestures of listeners, and other emphatic signals indicate to a speaker that the floor is still his or hers and the topic is of interest. This is the following example of minimal responses (Fishman 1983, in Coupland and Jaworski, 1997):

$7 \quad$ F: tion? (2)

$\rightarrow$ M: $\quad$ Nhhhmmmm $(($ no $))(=)$
Because they needed more teachers because of the increase enroll-

The last mentioned interactional strategy was making statements. According to Fishman (1983, in Coupland and Jaworski, 1997), a statement does interactional work 


\section{Rowanne Marie Ramos Maxilom}

in a way that it fills a space and that it may also yield a response. Yet, such 'statements' display an assumption on the part of the speaker that the attempt will be successful in the manner that if it will be understood, if the statement is of interest, there will be a response (Fishman, 1893 in Coupland and Jaworski, 1997). An example, as taken from the study, would be the speaker speaking a passage or reading a text aloud.

To be able to grasp the nature of the social world and to participate in it, one must depend on our capability as social interactants (Enfield and Levinson, 2006 in Heritage and Clayman, 2010). Fishman's (1983, in Coupland and Jaworski, 1997) concept of the 'work' involved in conversations, interactional strategies are vital indeed to the continuation of the conversation because it is through interaction that actions are made every day.

Another field in the course of pragmatics and discourse analysis is the discourse anaphora. In this field, it is an approach whereby an item in the previous context is referred by an element. There are four (4) types of theoretical models under discourse anaphora according to Huang (1989). First is the topic continuity or distanceinterference model which refers to the sense of the topic being talked about in the discourse. The continuity of topic in discourse is measured primarily by factors such as linear distance (the number of clause/sentence between the two mentions of a referent), referential interference (the number of interfering referents), and thematic information (maintenance or change of the protagonist) (Huang 1989).

Second is the hierarchy model, which is an approach that assumes that the most essential factor that affects anaphoric selection. From this assumption follows the central empirical prediction of the theory, namely, mentions (initial or non-initial) at the beginning or peak of a new discourse structural unit tend to be done by a full NP, whereas subsequent mentions within the same discourse structural unit tend to be achieved by a reduced anaphoric expression (Huang 1989). Forms of structural units in discourse can be in turns, paragraphs, episodes, events and themes. The main focus of this model is that the structure in discourse of anaphoric distribution should be accounted for.

Third is the cognitive model which refers to the primary concept that the cognitive processes such as activation and attention regulate the anaphoric encoding. Huang (1989) pointed out that a distinction should be made between the cognitive status of a particular referent and the means by which that referent achieves a particular cognitive status.

In addition, the identifiability and the activation of a referent which Lambrecht (1994) names it is a further difference that can be made. Identifiability refers to the addressee's knowledge state of a referent, i.e. whether or not a discourse representation of a referent has already been stored in the addressee's mind, whereas activation refers to the addressee's consciousness state of the current cognitive representation of an identifiable referent has already been activated, has merely been 
semi-active, or has simply been inactive at the time of utterance (e.g. Chafe, 1976, 1987; Lambrecht, 1994; but see Chafe, 1994: 54, for a slightly different view) (Huang, 1989).

(3) This example is from Huang (1989, p.163):

C1. A : Zhe qunzi zhen piaoliang! this dress really (be) pretty

C2. Shei mai de? Who buy SD

C3. B : Ta mai de 3SG buy SD

E1. A : What a pretty dress!

E2. Who bought (it)

E3. B : He (e.g. my boyfriend) bought (it)

Last is the pragmatic model which refers to the projection of anaphoric distribution in discourse is the systematic interaction of some general pragmatic strategies such as Levinson's (1991, 1995) Q-, I-, and M-principles.

(4) The example is from Huang (1994) in Chinese:

C1. A : Cai Lin zai yinhang gongzuo Cai Lin in bank work

C2. B : Ta airen ne 3SG spouse $\mathrm{Q}$

C3. A : $\varnothing$ haoxiang zai xintuo gongsi seem in trust company

C4. Ao Cai Lin unian hai qu le tang Xianggang Oh Cai Lin last year also go PFV CL Hongkong

E1. A : Cai Lin works in a bank

E2. B : How about her husband

E3. A : (He) seems to work in a trust company

E4. A : Oh Cai Lin even visited Hongkong last year

In analyzing discourse, particularly in a conversation, correct assessment of the addressee's knowledge state is not easy and occasionally mistakes will occur. These mistakes can be considered as errors and production of such in the conversation will sometimes lead to anaphoric repairing.

There are four types of anaphoric repairs found in conversations. (1) self-initiated selfrepair, (2) self-initiated other-repair, (3) other-initiated self-repair and (4) otherinitiated other-repair. In self-initiated self-repair, there is frequently an explicitly or implicitly self-initiated check sequence followed by a pause between it and the speaker's repair (Huang, 1989). 
Rowanne Marie Ramos Maxilom

The example of self-initiated self-repair (Sacks and Schegloff, 1979: 19) is the following:

A : ... well I was the only one other than than the uhm tch Fords?. uh Mrs. Holmes Ford?

B : (pause)

A : You know uh//the the cellist?

B : Oh yes, She's she's the cellist.

A : Yes

$\mathrm{B}: \mathrm{Ye} / / \mathrm{s}$

A : Well she and her husband were there.

Smith (2008) pointed out in his research on 'Methodological Hurdles in Capturing CMC data: The Case of the Missing Self-Repair' that learner self-repair or selfcorrection has been explored in a variety of educational contexts from various theoretical perspectives and with a focus on both native speakers and second/foreign language learners. He studied twenty-three interactions in the chat logs recorded. The participants use English as their native language and the target language for the research was German. This is similar to the present study in a way that errors are found and were repaired by using the second/foreign language learners. Clearly, in the present study, target language is also English.

In self-initiated other-repair, the speakers have started the repair mechanism themselves; it is most likely that they will do the actual repair (Huang 1989).

Example of self-initiated other-repair translated from Chinese (Huang,1989) is as follows:

(6)

\section{A : There is uhm the person who's married to a senior cadre's son uhm uhm the one who's quite pretty what's (her) name \\ B : Oh Fan Chunxiao \\ A : Yes, Fan Chunxiao}

Parkson's (2007) article on "Other-initiated repair acts. Preventing and Detecting Miscommunication: Analysis of Estonian Information Dialogues" defined selfinitiated other-repair as a reformulation where the hearer initiates the repair and suggest her own interpretation of the problematic place. In addition, a study done by Hosoda (2000) on "Other-Repair in Japanese Conversations between Nonnative and Native Speakers" stipulated that each time a speaker produces what may be taken as a problem by a hearer, and the hearer notices the problem, the hearer has a choice of repairing 'the problem' or not as well as initiating repair or not. On the other hand, 
other-initiated self-repair shows that the hearer systematically withholds the otherinitiated recognition search sequence until he or she sees that no self-initiated selfrepair of the problematic referential form is likely to occur (Huang, 1989).

This is the example of other-initiated self-repair (Huang, 1989):
A : Xiao Zhao has gone back to Zhenjiang
B : Which Xiao Zhao
A : Zhao Lisha
$\mathrm{B}: \mathrm{Oh}$

In his research on 'Repair-initiating particles and um-s in Estonian spontaneous speech', Hennoste (2005) suggested that other-initiated self-repair is initiated by hearer, who has found some problems in the speaker's previous text. He called it as next-turn repair instead of other-initiated self-repair.

Lastly, in other-initiated other-repair, the hearer suspects that the person being talked about might be someone he/she can identify. To confirm their suspicions, they launch another-initiated other-repair, which is then confirmed by the speaker at the next turn available (Huang, 1989).

Here's an example of other-initiated other-repair (survey of English, cited in Geluykens, 1994).

A: and old Joe who's very [ $\left.{ }^{\curvearrowright}: \mathrm{m}\right]$ skeptical about these things he's [ə:m]- - you know \# he's he was /quite/ 'very im'pressed with *this this/' 'Guinness \# a: *Joe.Joe Lemon m*

A: /Joe 'Lemon \#/^yeah \#.* (...)

An article by Besnier (1989) on "Informative withholding as a manipulative and collusive strategy in Nukulaelae gossip" defined other-initiated other-repair as a repair that is accomplished in its entirety by someone other than the author of the problematic utterance. He also added that some of these choices have the potential of being perceived as face-threatening acts, that is, verbal acts that undermine another person's presentation of self as a rational agent, because they "may imply that self is misguided and incompetent" (Brown and Levinson 1987:38).

In general, as Huang (1989) stated that anaphoric distribution in discourse is a very complex phenomenon, involving, among other things, structural, cognitive and pragmatic factors that interact with each other. However, Huang (1989) also identified three main approaches to discourse anaphora. First is the topic continuity model i.e. in discourse, anaphoric distribution is essentially determined by the continuity of the topic. Second is the hierarchy model in which the anaphoric distribution is determined 


\section{Rowanne Marie Ramos Maxilom}

by its hierarchical structure. Third is the cognitive model which states that anaphoric distribution is determined by cognitive factors such as memory and attention. Last is the pragmatic model which was expressed by Huang $(1987,1991,1994)$ and Levinson $(1987,1991)$ in a general neo-Gricean pragmatic theory of anaphora.

To summarize, the pair conversations of the BS ICT students will be analyzed using the frameworks and theories concerning interactional strategies and anaphoric repairs given by the Fishman (1983) and Huang (1989), respectively. The recorded pair conversations and its results will lead to the discovery and understanding of the choice of strategies and its importance to the persistence of interaction in a conversation as well as the interpretation of the ways of how the students repair their statements when making anaphoric mistakes.

The purpose of this study was to identify and analyze the interactional strategies and the anaphoric repairs used in the recorded pair conversations of Bachelor of Science in Information and Communication Technology (ICT) students who were taking the course Interactive English in the Academic Year 2012-2013. This study sought answers to the following questions: (1) What interactional strategies are evident in the interaction of the students based on Fishman (1983, in Coupland and Jaworski, 1997)?

(1.1.) asking questions, (1.2.) asking 'd'ya know', (1.3.) attention beginnings,

(1.4.) minimal response, and (1.4). making statements; (2) What are the types of anaphoric repairs found in the interaction between the two students based on Huang (1989)?

(2.1.) self-initiated self-repair, (2.2.) self-initiated other-repair, (2.3.) other initiated self-repair other initiated other-repair

\section{RESEARCH METHODOLOGY}

\subsection{Research Design}

This study was qualitative-descriptive in form for its reliance on the words, phrases and sentences that were uttered in the conversations that were recorded. The researchers' analysis aimed to identify the interactional strategies used in the conversation and anaphoric repairs of the BS Information Communication Technology students taking up Interactive English (ICT 135).

This study also employed the purposive sampling for its basis on the criteria that the participants should be specifically enrolled in an ICT 135 course and convenience sampling procedure because of the participants' accessibility and proximity to the researchers since they are within the campus.

\subsection{Research Environment}

This study was done in a classroom setting, during their class schedule. The pair recording was in a closed, partly controlled environment since the topics of the conversations of the participants were already given by means of drawing lots. So, the 
conversations were not naturally initiated but were started with already a topic in mind.

\subsection{Research Participants}

The participants of this study were ten (10) pairs of BS ICT block section students. All the participants were on the same degree program and on the same year level. They were $2^{\text {nd }}$ year students. Participants should all be taking up Interactive English.

\subsection{Research Tool and Instrument}

The researchers used a video recorder to record the conversations of the students. Ten pair/dyadic conversations were recorded. The researchers utilized these conversations as the source of the data in the study. These conversations were then analyzed giving importance to the interactional strategies and anaphoric repairs in talking that will be present in the data. Aside from the recorder, the researchers also used profiles as to acquire the profile of the participants.

\subsection{Research Data}

The data of this research were ten (10) pair conversations between BS ICT students. The ten (10) dyadic conversations were analyzed according Fishman's (1983, in Coupland and Jaworski, 1997) interactional strategies and Huang's (1989) anaphoric repairs.

\subsection{Research Procedures}

The study used the purposive sampling procedure. A transmittal letter was given to the subject instructor asking permission to video record the conversations of her students during their pre-midterm exam as well as for prerogative to give instructions to the class concerning the conversation and the assurance that the data will be kept confidential.

The subject instructor already paired her class and gave the main instructions which covered her requirements for her exam: (1) the students were to pick a paper from a bowl which contains a question which would be their topic, (2) the students were given a one-minute thinking time, (3) students must speak and interact for this was the basis of their grades and (4) they must converse for seven (7) minutes.

Ten (10) pair conversations were examined. The criteria given for the participants were considered.

The researchers recorded ten (10) pair conversations. One of the researchers was assigned to five (5) pairs and one was on the other five (5) pairs. Then designation of the encoding task and analysis was discussed. A pilot study was also conducted in order to determine whether the two sub-problems are valid. Two (2) pair conversations already recorded beforehand were transcribed and analyzed based on the sub-problems. 


\subsection{Data Analysis}

The data were subjected to a qualitative-descriptive form. The ten (10) recorded pair conversations among BS ICT students were examined to answer the first sub-problem which was to identify what interactional strategies occurred in the recorded conversations of the BS ICT students based on Fishman (1983, in Coupland and Jaworski, 1997). These interactional strategies were: asking questions, asking 'D'ya know', attention beginnings, minimal response, and making statements.

Results were presented showing the interactional strategies that are present in the pair conversations of the BS ICT students based on Fishman's (1983, in Coupland \& Jaworski, 1997) framework. To answer the second sub-problem, the anaphoric repairs based on Huang (1989) namely: Self-initiated self-repair, self-initiated other-repair, other initiated self-repair and other initiated other-repair were be identified and analyzed.

\section{FINDINGS AND DISCUSSION}

Using the framework of Fishman (1983), the data revealed the following interactional strategies from the ten (10) recorded pair conversations of 20 BS ICT students. As presented in Table 1, each of the interactional strategy has a corresponding frequency and percentage.

Table 1: Interactional strategies that are evident in the recorded pair conversations of BS ICT students

\begin{tabular}{lll}
\hline Interactional Strategies & $\mathrm{F}$ & $\%$ \\
\hline Asking Questions & 94 & $65.73 \%$ \\
Minimal Responses & 47 & $32.87 \%$ \\
Making Statements & 2 & $1.40 \%$ \\
Asking 'D'ya Know' & 0 & $0 \%$ \\
Attention Beginnings & 0 & $0 \%$ \\
\hline Total & 143 & $100 \%$ \\
\hline
\end{tabular}

The data revealed that there were three interactional strategies employed by the BS ICT students in their recorded pair conversations. Most of the students' conversations involved primarily on Asking Questions, Minimal Responses, and Making Statements.

The researchers recognized that there is always the need for interaction. With this in mind, a "certain amount of work must necessarily be done by the participants if the interaction is to go smoothly" (Kollock, et al., 1985, p. 35). As supported by Fishman (1983, in Coupland and Jaworski, 1997), there are always attempts at beginning, sustaining, and stopping talk in any setting in which conversation is probable and possible. Hence, the presence of interactional strategies will maintain or begin a conversation. 
It is expected to discover that Asking Questions got the highest percentage of 65.73\%. In using this interactional strategy, the students were able to induce further utterances because by asking such questions, speakers expect to receive a response.

Minimal Responses, sometimes called as back-channels, which got the second highest percentage of $32.87 \%$ also allowed the students to relay to the other that the topic is of interest. This encourages the flow of the conversation.

Asking Questions. Questions are treated as standing in paired relation because they evoke further utterance (Fishman, 1983, in Coupland and Jaworski, 1997).

Sample 1 (Lines 10-21)

10. S2: Why?

11. S1: Because my classmates say that.. my polo is good.

12. S2: And you believe?

13. S1: Yes.

14. S2: Are you sure of that?

15. S1: Yes.

16. S2: What made you say?

17. S1: What?

18. S2: Um. What made you say that the polo is good?

19. S1: The color.. and the brand.

20. S2: What if they lied to you? Do you believe?

21. S1: No.

The follow-up of questions from sample 1 (e.g. 'why', 'and you believe', 'are you sure of that' etc.) are always answered with questions and thus lengthening the conversations. Asking questions are sometimes used to seek 'orientation information', such as clarification or elaboration of a topic or checking on the same time or place of event (Mesthrie et. al, 2000). In this case, from the sample, there is the need of going into detail about the topic, which was about the polo, which resulted to the need of asking questions. The strategy worked in the way that all of the questions were answered and continued the conversation. Talbot (1998, in Chan, 2008) stated that one function of questions is to elicit responses from the listener refers. These responses or the questions answered extended the conversation. This is in agreement with Fishman's (1983, in Coupland and Jaworski, 1997) study that questions are to be coupled with an answer and thus retaining the conversation. Yet, asking questions could also be useful in the way that it opens to another topic as what the researchers observed from below:

Minimal Responses. These are forms such as yeah or right or $m h m$ (Coates, 2004, p. 87).

Sample 2 (Lines 42-48) 
Rowanne Marie Ramos Maxilom

S1 : Because in teaching the child what is wrong, he will become right,

S2 : Yah.

$\mathrm{S} 1$ : He will become um careful. As adults, someone older than them should help them to guide them.. in the proper way.

S2 : *nods* yes.

As observed from sample 2, the speaker (S2) employed minimal responses such as 'yah' and 'yes' to show that the topic is of interest. Their usages were intended to support the matter on the floor. Nods are also considered as minimal responses and this was used for encouragement. Coates (1997, in Mesthrie et. al, 2000) sees minimal responses as highly cooperative. This interactional strategy are analyzed, not as speaking turns in their own right but as conversational supports (Mesthrie et. al, 2000). This explains sample 3. Indeed, minimal responses support the conversation and prevent it from ending because when they are uttered or provided by the speakers or listeners, it indicates that the one who uttered it is of attention and is still involved in the conversation.

Based on the transcribed data, it was found that Minimal Responses had two purposes based on the recorded conversations: encourages the speaker on the topic or it ends a topic.

Making Statements. Statements fill a space and may also provide for a response (Fishman, 1983, in Coupland and Jaworski, 1997).

Sample 3 (Lines 91-101)

S1 : William Shakespeare?

S2 : Yeah.

S1 : So, was it in Old English or was it translated to Modern English?

S2 : It was in Old English.

S1 : Old English?

S2 : *nods*

S1 : So, you were like, "Romeo, oh Romeo.."

S2 : Yes.

S1 : Yes.. Did you like it? Did you like Romeo?

S2 : Yeah, a little bit.

Fishman (1983, in Coupland and Jaworski, 1997) explained that these statements could be a passage or a text read aloud. In this case, from sample 4, a famous line from a book was mentioned. The utterance of 'Romeo, oh Romeo' displayed an assumption on the part of the speaker that it will be comprehended. Based on the response from the sample after the statement was being sad, it showed that the speaker's assumption was correct and the line was comprehended by the listener. It can be seen that through that statement, the conversation moved on. 
The interactional strategies Asking 'D'ya Know' and Attention Beginnings were not present in the present study's transcribed data compared to Fishman's (1983, in Coupland and Jaworski, 1997) where in Asking 'D'ya Know' was used effectively as well as Attention Beginnings.

Asking D'ya Know was employed by American couples in Fishman's study (1983, in Coupland and Jaworski). The participants in the present study were not native speakers of the language used in the conversation. There is a racial as well as a cultural difference in this study's and Fishman's (1983) conversations. This could explain as to why Asking D'ya Know was not employed. It is a term rarely or, probably, never used in the Philippine context.

On the other hand, there were no occurrence of Attention Beginnings since the conversations were not naturally initiated but was started with a question given by the instructor and since, the participants focused mainly on asking questions or elaborating a topic rather than bringing attention to themselves through providing new and totally different topics than only they, themselves, could be interested. Also, culturally speaking, Attention Beginnings are seldom used in the conversations in the Philippines.

Using the framework of Huang (1989), the data uncovered the following anaphoric repairs of the 10 recorded pair conversations of 20 BS ICT students. As shown in Table 2, each of the anaphoric repair has a matching frequency and percentage.

Table 2: The types of anaphoric repairs that are found in the recorded pair conversations of BS ICT students

\begin{tabular}{lll}
\hline Anaphoric Repairs & F & $\%$ \\
\hline Other-initiated Self-Repair & 5 & $55.55 \%$ \\
Self-initiated Other-Repair & 4 & $44.44 \%$ \\
Self-initiated Self-Repair & 0 & $0 \%$ \\
Other-initiated Other-Repair & 0 & $0 \%$ \\
\hline Total & 9 & $100 \%$ \\
\hline
\end{tabular}

The data showed that there were 2 anaphoric repairs used by the BS ICT students in their 10 recorded pair conversations. The types of anaphoric repairs that were evident in the recorded pair conversations were the Other-initiated Self-Repair and Selfinitiated Other-Repair.

The present study showed that Other-initiated Self-Repair got the highest percentage of $55.55 \%$. In line with this, the students were prone in correcting their own errors. The participants used repetition as to repair the problematic expression. As Sidnell (2010) stated that repair may also be initiated by a repeat without any question word. Self-correction of speech and writing, and the correction of others in conversation ("I can't understand what you say"), in classrooms, and over editorial desks is an 


\section{Rowanne Marie Ramos Maxilom}

unending business, one that determines the outlines of our speech just as acceptance determines its mass (Schegloff et al., 1977)

Next, Self-initiated Other-Repair came second with the percentage of $44.44 \%$. This result shows that the student, who is speaking, had given a potentially problematic anaphoric expression, was repaired by the student who's listening to the topic at hand.

On the other hand, Self-initiated self-repair and Other-initiated other-repair did not occur in the pair conversations or BS ICT students. This contradicts the result of Huang's (1989) study. In his research, Self-initiated self-repair was by far the most common type of anaphoric repair. Comparing it to the present study, the results did not support Huang's (1989) results. The absence of the types of repairs mentioned above implies that both the student-speaker and the student-listener agreed to the reference mentioned within their conversations. Another interpretation is that since the recorded pair conversations were the participants' pre-midterm exam, the conversations partly controlled. It is partly controlled since the participants were given instructions and the topics were also limited and chosen by the teacher. The researchers also considered their conversations as structured, not a natural one. The primary goal of their conversations was for one student to ask questions and the other student to give answers. There was a certain order in the conversations. With this, self-initiated self-repair and other-initiated other-repair did not occur because of the structured pair conversations. The participants were expected to ask questions and give answers, they were not able to correct or repair the conversations. Krippendorff (2009) stated that the unwillingness to repair problematic conversations amounts to acquiescence to constraints that are typical of discourses and the construction of institutional realities.

Other-initiated Self-repair. This type of repair shows that the hearer systematically withholds the other-initiated recognition search sequence until he or she sees that no self-initiated self-repair of the problematic referential form is likely to occur according to Huang (1989).

Sample 4 (lines 54-63)

S2 : Yes, cause maybe if I'm the parent and I have a daughter maybe I won't, I will not, I might never allow her to, to have a boyfriend whiles he's studying college until she finishes and her major college. If I were you, I think I'll just show my seriousness to her and then you should know your...

S1 : Yeah, my limits.

S2 : Your limits and your true ...

S1 : True Colors. *laughs

S2 : Your true self to them. 
The sample transcript which was demonstrated by the participants shows that whenever the hearer or listener of the conversation detects some problems or does not recognize the reference being talked about by the speaker, the listener will then initiate the said repair. A study done by Wong (2000) had similar observation to the present study. In her study, she stated that in Second Language Acquisition (SLA), repair is largely limited to correction of error or to clarification of communication made problematic because of linguistic error, while in Conversational Analysis (CA), repair refers to efforts to deal with any problems in speaking, hearing, or understanding of the talk. In addition, confirmation checks, clarification requests, restatements, repetitions, understanding checks, and the like, all fall within the domain of repair in CA work, regardless of whether the utterances are linguistically correct.

In the recent study, the researchers observed that the BS ICT students used repetitions (e.g. s1: yeah my limits. s2: your limits and your true...) to initiate the repair in order for the problematic utterance to be repaired. A further comparison to Wong's (1989) and the present study is that, her participants were non-native speakers of English just like in the present study, the BS ICT students were also non-native speakers of English.

Self-initiated other-repair. "The speakers have started the repair mechanism themselves; it is most likely that they will do the actual repair" (Huang, 1989, p.170).

Sample 5(lines 79-83)

S1 : You're brave, you have much experience than me. I only had 3 girlfriends and two were is just a joke.

S2 : Joke? *laughs

S1 : Yeah, I didn't know, we were really young, we don't think that much. Everything was just a game.

The researchers observed that when a student or the speaker gave an utterance with a potentially problematic expression and did the initiation of repair, the other student or the listener repaired it with a non-verbal signal. The repair was followed by a laugh or a nod. In lieu with this, a study done by Hosoda (2000) stated that non-verbal features of the interaction revealed that the other-repair within his data consistently followed certain non-verbal signals by the former speaker. The non-verbal signals in Hosoda's (2000) data include eye gaze, posture, raised eyebrows, laughter, nods, pointing to oneself, and head tilts.

Based on the gathered and analyzed data, the results differed compared to that of Fishman (1983) and Huang (2000). Some interactional strategies that were expected to be present did not occur as well as some of the anaphoric repairs. Although the data did provide new interpretations of both the strategies and repairs with regard to its usage and its purpose during the conversation. Some interactional strategies were found to be used in different ways while some are found to have a different purpose 


\section{Rowanne Marie Ramos Maxilom}

not mentioned in the original study. On the other hand, self-initiated self-repair and other-initiated other repair did not occur in the present study, because of two factors. First is the participants' agreement to the reference mentioned and second are the structured pair conversations by the participants.

Overall, the interactional strategies that occurred in the recorded pair conversations of the BS ICT students are the following: asking questions, minimal responses and making statements. Furthermore, the types of anaphoric repairs that were evident in the recorded pair conversations of BS ICT students are as follows: other-initiated selfrepair and self-initiated other-repair.

\section{CONCLUSION}

With all the important and main finding unveiled, the researchers have come up with the following conclusions: The use of interactional strategies depends on the students and on the flow of conversation as well as on the topic on the floor. Asking questions occurred most than the other interactional strategy present and was found very effective since all the students paired every question with answers. Minimal responses were also evident and were used along with making statements. In every conversation, not all strategies were employed by the students; some only used one, others used two. There are indeed differences in every speaker in using the interactional strategies. Asking Questions was found to encourage the conversation in two ways. First, it invoked more utterance on the same topic through follow-up questions or it elaborates a topic and second, it opens another topic that totally deviated from the first which made the conversation move on.

The interactional strategy, Minimal Responses, was found to have two purposes. The first purpose, as observed from the data, was to continue the topic and the conversations itself. The second purpose was to show that the topic at hand is not on the interest of the other student and thus the speaker changes the topic.

The initiation of repair and the repair itself also depends on the students and their knowledge of the reference being talked about. On the present study, only two types of anaphoric repairs were used by the students. Other-initiated self-repair occurred more frequently in the conversations. Repetitions of the problematic expressions were executed to initiate the repair mechanism. Factors are: the listener has a problem on the reference being talked about and the speaker did not clearly state his or her intended utterance.

On the other hand, self-initiated other-repair came next to the previous repair mentioned. Other than initiating the repair by a verbal signal, the students initiated the repair mechanism by a non-verbal signal. This shows that not only repairs are done my verbal signals, but also in non-verbal gestures.

Since the present study's environment was in a classroom setting and the students' conversations were controlled by giving them a topic from their instructor, future 
researchers can try to let their participants choose the place they want to converse and the topic they want to dwell on and be comfortable with it.

Given that the use of English language was required by the ICT 135 class, the participants were obliged to speak in the language mentioned. Future researchers can let their participants use their Mother Tongue or the Cebuano language as the language to be used in their research, regardless of the subject taken up by the participants. In using the Mother Tongue, the participants would be more comfortable in speaking providing a more natural and unrestricted flow of conversation.

\section{REFERENCES}

Besnier, N. (1989). Informative withholding as a manipulative and collusive strategy in Nukulaelae gossip. Retrieved September 27,2012,from http://pacific.socsci.uva.nl/besnier/pub/Information_Withholding.pdf

Bennet, M. \& Jarvis, J. (1991) Communicative function of minimal responses in everyday conversation. Retrieved July 11, 2015 from http://content.ebscohost.com/pdf14_16/pdf/1991/JSY/01Aug91/9707140321.pd $\mathrm{f} ? \mathrm{~T}=\mathrm{P} \& \mathrm{P}=\mathrm{AN} \& \mathrm{~K}=9707140321 \& \mathrm{~S}=\mathrm{R} \& \mathrm{D}=\mathrm{a} 9 \mathrm{~h} \& \mathrm{EbscoContent}=\mathrm{dGJyMNXb} 4 \mathrm{k}$ Sep684yOvqOLCmr0qeprdSrqm4TLWWxWXS\&ContentCustomer=dGJyMP GqsUy0prVLubm\%2Fa7nb5ofx6gAA.

Bonvillian, N. (2003). Language, communication and culture: The meaning of messages (4 ${ }^{\text {th }}$ Ed.). New Jersey: Pearson Education, Inc.

Chan, N. (2008). Gender stereotypes: a sociolinguistic study ofthe amazing race asia season two". Retrieved December 06, 2015 from http://www.english.hku.hk/LCOM\%20paper/LCOM\%20papers\%20new,\%20re v/2008\%20vol2/4\%20Gender\%20stereotypes.pdf

Coates, J. (2004). Women, men and language: a sociolinguistic account of gender differences in language ( $3^{\text {rd }} \mathrm{Ed}$.). UK : Pearson

Coupland, N. \& Jaworski, A. (1997).Modern linguistics: sociolinguistics - a reader and a coursebook. New York: St. Martin's Press, Inc.

Hennoste, T. (2005). Repair-initiating particles and um-s in Estonian spontaneous speech. Retrieved September 27, 2015, from http://www.iscaspeech.org/archive_open/archive_papers/diss_05/dis5_083.pdf

Gumperz, J. (2008). Interactional sociolinguistics: a personal perspective. Retrieved $\begin{array}{llll}\text { October } & 12, & 2015 & \text { from }\end{array}$ http://www.maxwell.syr.edu/uploadedFiles/exed/sites/ldf/Academic/Gumperz.p df

Hosoda, Y. (2000). Other-Repair in Japanese Conversations between Nonnative and Native Speakers. Retrieved September 27, 2015, from http://www.escholarship.org/uc/item/9rb6b1m6

Huang, Y. (1989). Discourse anaphora: Four theoretical models. Journal of Pragmatics. 32, 151-176.

Indonesian Journal of EFL and Linguistics, 4(1), 2019 
Rowanne Marie Ramos Maxilom

McCarthy, M. (2003).Talking back: "small" interactional response tokens in everyday conversation. Retrieved July 10, 2015 from http://www.cs.cmu.edu/afs/cs.cmu.edu/Web/People/dod/papers/mccarthy2003.p df

Mesthrie, R., Swann, J., Deumert, A. \& Leap, W. (2000) Introducing sociolinguistics $\left(2^{\text {nd }}\right.$ Ed.). New York: Edinburgh University Press.

Norrick, N. (2008). Negotiating the reception of stories in conversation: teller strategies for modulating response. Retrieved December 06, 2012 from http://benjamins.com/series/ni/18-1/art/07nor.pdf

Parkson, S. (2007). Other-initiated repair acts. Preventing and Detecting Miscommunication: Analysis of Estonian Information Dialogues. Retrieved September 27, 2012, from http://www.speech.kth.se/ rolf/NGSLT/gslt_papers_2006/TermPaperParkson.p df

Pearson, J., Nelson, P., Titsworth, S., \& Harter, L. (2003). Human communication. New York: McGraw-Hill.

Redeker, G. (2006). Gendered interaction strategies in televised panel interviews. $\begin{array}{llll}\text { Retrieved July } & 10, & \text { from }\end{array}$ http://www.let.rug.nl/redeker/RedekerSocioling2006.pdfll

Schegloff, E., Jefferson, G., \& Sacks, H. (1977). The preference for self-correction in The organization of repair in conversation. Retrieved January 22, 2013 from http://www.liso.ucsb.edu/Jefferson/Repair.pdf

Sidnell, J. (2010). Conversational analysis: an introduction. United Kingdom: WileyBlackwell

Sidnell, J. (Ed.).(2009). Conversational analysis: comparative perspectives. New York: Cambridge University Press.

Smith, B. (2008). Methodological Hurdles in Capturing CMC data: The Case of the Missing Self-Repair. Retrieved September 27, 2012, from http://lit.msu.edu/vol12num1/pdf/smith.pdf

Stockwell, P. (2007). Sociolinguistics: a resource book for students ( $2^{\text {nd }}$ Ed.). New York: Routledge.

Tannen, D. (2005). Interactional sociolinguistics as a resource for intercultural $\begin{array}{llll}\text { pragmatics. } & \text { Retrieved } & \text { October } & 12\end{array}$ http://www9.georgetown.edu/faculty/tannend/pdfs/interactional_socioling_as_a _reource_for_intercultyral_interaction.pdf

Wardhaugh, R. (2010). An introduction to sociolinguistics $\left(6^{\text {th }}\right.$ Ed.).United Kingdom: Wiley-Blackwell. 